\title{
cha.OPEN
}

\section{Patterns of cost-related medication underuse among Canadian adults with cancer: a cross-sectional study using survey data}

\author{
Omar Abdel-Rahman MD MSc, Scott North MD MHPE
}

\section{Abstract}

Background: Cost-related medication underuse (CRMU) has been reported within the general population in Canada. In this study, we assessed patterns of CRMU among Canadian adults with cancer.

Methods: This is a cross-sectional study using survey data. We accessed data sets from the 2015/16 Canadian Community Health Survey (CCHS) and reviewed the records of adults ( $\geq 18 \mathrm{yr}$ ) with a history of cancer who were prescribed medication in the previous 12 months. We collected information about sociodemographic features, health behaviours and CRMU, and conducted a multivariable logistic regression analysis for factors associated with CRMU.

Results: A total of 8581 participants were eligible for the current study. In the weighted multivariable logistic regression analysis, the following factors were associated with CRMU: younger age (odds ratio [OR] 2.55, 95\% confidence interval [CI] 1.79-3.63), female sex (male sex v. female sex OR $0.62,95 \% \mathrm{Cl} 0.44-0.88$ ), Indigenous racial background (Indigenous v. White OR 2.37 , 95\% Cl 1.493.77 ), unmarried status (OR 1.59, 95\% Cl 1.09-2.30), poor self-perceived health (excellent v. poor self-perceived health OR 0.36 , $95 \% \mathrm{Cl}$ 0.17-0.77), lower annual income (<\$20 000 v. income $\geq \$ 80000$ OR 3.08, 95\% Cl 1.75-5.41) and lack of insurance for prescription medications (OR 2.49, 95\% Cl 1.77-3.50).

Interpretation: The toll of CRMU among adults seems to be unequally carried by women, racial minorities, and younger (< 65 yr) and uninsured patients with cancer. Discussion about a national pharmacare program for people without private insurance is needed.

ccording to the Canadian constitution and the Canada Health Act, health care is a provincial jurisdiction, but each province needs to provide medically necessary interventions to receive federal transfer payments. ${ }^{1}$ Therefore, and with very few exceptions, provincial health care insurance plans cover all procedures and treatments deemed medically necessary for cancer treatment. ${ }^{2}$

However, most jurisdictions do not cover supportive care medications as part of the cancer treatment plan, and the onus is on the patient to purchase their own medications. Patients who do not have drug coverage need to pay full out-of-pocket costs for these medications, and those with drug plans may have copayments according to the terms of their plans.

In recent years, there has been a move to using oral medications instead of intravenous medications as a premedication to chemotherapy because of decreases in the supply of intravenous medications and the need to reduce the length of time spent administering intravenous medications in chemotherapy clinics. This practice has further shifted the burden of purchasing supportive care medications to the patient. ${ }^{3}$ Moreover, provincial insurance plans apply only to eligible people, including Canadian citizens, permanent residents and some residents on temporary visas. It is not uncommon for some groups, such as temporary workers or other migrants, to be ineligible for health care services, including cancer care. Moreover, in some provinces, Canadian citizens and permanent residents have to wait 3 months before their provincial coverage starts if they are moving from outside of the country. ${ }^{4}$

All the above factors contribute to the ongoing problem of cost-related medication underuse (CRMU), where people either do not fill a prescription or skip doses of a prescribed medicine because of financial hardship and lack of prescription medication coverage. ${ }^{5}$ Although the prevalence of CRMU in Canada and associated factors have been previously evaluated among patients without cancer, ${ }^{6-8}$ the prevalence

Competing interests: Omar Abdel-Rahman declares having recently participated on an advisory board for Eisai Canada for a topic unrelated to the manuscript. No other competing interests were declared.

This article has been peer reviewed.

Correspondence to: Omar Abdel-Rahman, omar.abdelsalam@ahs.ca CMAJ Open 2021. DOI:10.9778/cmajo.20200186 
and associations of CRMU among patients with cancer and survivors require further study in a national cohort. A cancer diagnosis brings with it long-term socioeconomic and medical challenges. Many cancer survivors are left with a host of medical problems and treatment-related disabilities that prevent them from working to provide for themselves, their families and their medical expenses. ${ }^{9,10}$ Thus, the burden of CRMU is expected to be higher in this subgroup.

Our objective was to assess the patterns of CRMU among Canadian adults with cancer in a contemporary populationbased cohort. Our main hypothesis was that insurance coverage for prescription medications and higher socioeconomic status are associated with less CRMU among adults with a history of cancer in Canada.

\section{Methods}

\section{Study design and data source}

This study is a cross-sectional study using data from the Canadian Community Health Survey (CCHS). The CCHS is an annual national survey that provides population-level data on the social determinants of health, health behaviours and experiences of Canadians with the health care system. ${ }^{11}$ It thus provides a good data source to evaluate sociodemographic factors associated with nonadherence and underuse of prescribed medications.

It is estimated that the CCHS is representative of about 97\% of Canadians. Its sampling strategy follows a combination of area and phone list framing, in addition to random dialing in some health regions. Underrepresentation has been reported for people in some Quebec health regions, full-time members of the Canadian Armed Forces and people living in Indigenous settlements. Further information about the sampling strategy of the CCHS is provided in its publicly available documents. ${ }^{12}$ The current study is based on CCHS data sets for 2015/16 because detailed information about CRMU and insurance coverage was provided in these data sets.

\section{Study population}

We used the following criteria for cohort selection based on questions within CCHS data sets: adult (> $18 \mathrm{yr}$ ) participants with a history of cancer, defined by answering yes to whether or not the participant had cancer or had received a diagnosis of cancer, and with complete information about CRMU, defined by whether the participant did or did not fill or collect a prescription for medicine or skipped doses of their medicine because of cost in the previous 12 months (i.e. question PEX_090 of the survey). We excluded participants who were not prescribed a medication in the previous 12 months.

\section{Data collection}

We included the following variables from each participant, where available: age at survey completion, sex, racial background (White, Indigenous or other), marital status, income, insurance coverage for prescription medications (yes or no), type of insurance (governmental, employer, association or private), educational level, self-perceived health and mental health status, food security (defined by whether or not the participant had been worried that food would run out in the previous 12 months), working status in the previous week (working, absent or did not have a job) and emergency department visits and overnight hospital admission visits in the previous 12 months. Based on whether participants reported a current or past diagnosis of cancer, they were classified into current patients with cancer or cancer survivors. We reviewed the presence of self-reported comorbidities, namely asthma, chronic obstructive pulmonary disease, sleep apnea, fibromyalgia, arthritis, osteoporosis, hypertension, dyslipidemia, heart disease, stroke, diabetes mellitus, migraine, mood disorder and anxiety disorder. We coded marital status as married versus unmarried (i.e., common-law relationship, widow/ divorced/separated or single).

\section{Statistical analysis}

To account for the complex sampling approach of CCHS, we weighted all analyses. We used $\chi^{2}$ tests of categorical variables (age, insurance status and other sociodemographic characteristics) to determine differences between participants who did or did not have a history of CRMU. We used multivariable logistic regression to evaluate the factors associated with CMRU among all participants. This model included age at survey completion, sex, racial background, marital status, income, insurance coverage, educational level, self-perceived health and self-perceived mental health. We chose these factors based on previous studies evaluating CRMU in other jurisdictions. ${ }^{13}$ We did not include the presence of comorbidities in this model because of the potential for multicollinearity between the presence of comorbidities and self-perceived health and self-perceived mental health (i.e., the presence of comorbidities should correlate significantly with each of these variables), as well as between each of these comorbidities (e.g., between stroke and heart disease or between anxiety and mood disorders). This was not formally tested, as the number of participants reporting each comorbidity was very small. We did not use imputation methods and we excluded participants with missing variables from regression analyses.

To assess the impact of working status (i.e., unemployment) on CRMU, we conducted another multivariable logistic regression analysis among adults with cancer younger than 65 years, including the same variables as detailed above, with the exclusion of age (as we limited the analysis to participants $<65 \mathrm{yr}$ ) and including working status from the previous week. We focused on this age group under the assumption that many adults older than 65 years are retired and because, in many Canadian jurisdictions, these older adults would be covered by provincial senior drug plans.

We conducted all statistical analyses using STATA software (version 14.0).

\section{Ethics approval}

Because this study was based on the publicly available, open licence, anonymized data set, ethical approval was not required (as clarified by article 2.2 of the Tri-Council Policy Statement [TCPS2]). ${ }^{14}$ 


\section{Results}

The CCHS response rate was $59.5 \%$ in $2015 / 16$, with a total of 109660 participants. Appendix 1, Supplementary Figure 1, available at www.cmajopen.ca/content/9/2/E474/suppl/DC1, provides a flowchart for the participant selection process. A total of 8581 eligible participants were included in the current study, including 460 participants (weighted frequency 5\%) who reported CRMU and 8121 participants who did not report CRMU (weighted frequency 95\%).

Comparing both groups, participants with CRMU were more likely to be younger ( $<65 \mathrm{yr})$, be female, be of Indigenous ethnicity, have poor self-perceived health and mental health, have a higher burden of comorbidity, have lower income, be unmarried and lack insurance for prescription medications (Figure 1). Participants reporting CRMU were also more likely to be admitted to hospital and experience food insecurity in the previous 12 months (all $p<0.001$ ) (Table 1). Those patients were also more likely to visit the emergency department in the previous 12 months (mean 1.55 v. 0.62 visits). There was no apparent difference in CRMU between people with a current cancer diagnosis versus cancer survivors $(p=0.941$ ). Rates of CRMU within different Canadian jurisdictions are shown in Figure 2; the rate was highest in New Brunswick at $9.1 \%$ and lowest in Yukon at $0 \%$.

Within the cohort of younger participants $(<65 \mathrm{yr})$, CRMU was associated with not having a job. Among people who did not have a job, the frequency of CRMU was $10.6 \%$ compared with $5.2 \%$ among people who worked in the week before survey completion $(p<0.001)$. Moreover, $18.6 \%$ of younger $(<65 \mathrm{yr})$ participants with no insurance coverage reported CRMU in the 12 months before survey completion.

The following factors were associated with CRMU in weighted multivariable logistic regression analysis: younger age (odds ratio [OR] 2.55, 95\% confidence interval [C] 1.79 3.63), female sex (male v. female OR $0.62,95 \%$ CI $0.44-0.88$ ), Indigenous racial background (Indigenous v. White racial group OR 2.37, 95\% CI 1.49-3.77), unmarried status (OR $1.59 ; 95 \%$ CI 1.09-2.30), poor self-perceived health (excellent v. poor self-perceived health OR $0.36,95 \%$ CI $0.17-0.77$ ), lower annual income (< $\$ 20000$ v. $\geq \$ 80000$ OR 3.08, 95\% CI 1.75-5.41) and lack of insurance for prescription medications (OR 2.49, 95\% CI 1.77-3.50) (Table 2).

Among participants younger than 65 years, the same factors were associated with CRMU, including female sex (male v. female OR $0.63,95 \%$ CI 0.40-0.99), Indigenous racial background (Indigenous v. White racial group OR 2.52, 95\% CI 1.47-4.31), unmarried status (OR 1.75, 95\% CI 1.10-2.78), lower annual income $(<\$ 20000$ v. $\geq \$ 80000$ OR 2.82, 95\% CI 1.48-5.37) and lack of insurance for prescription medications (OR 3.14, 95\% CI 2.00-4.95) (Appendix 2, Supplementary Table 1 , available at www.cmajopen.ca/content/9/2/E474/ suppl/DC1). After controlling for all other variables in the model, including insurance and income, working status was not independently predictive of CRMU, (no job v. working in previous week OR 1.04, 95\% CI $0.65-1.66$ ). There was no clear evidence of multicollinearity between working status and insurance (unweighted Pearson $r=0.044$ ).

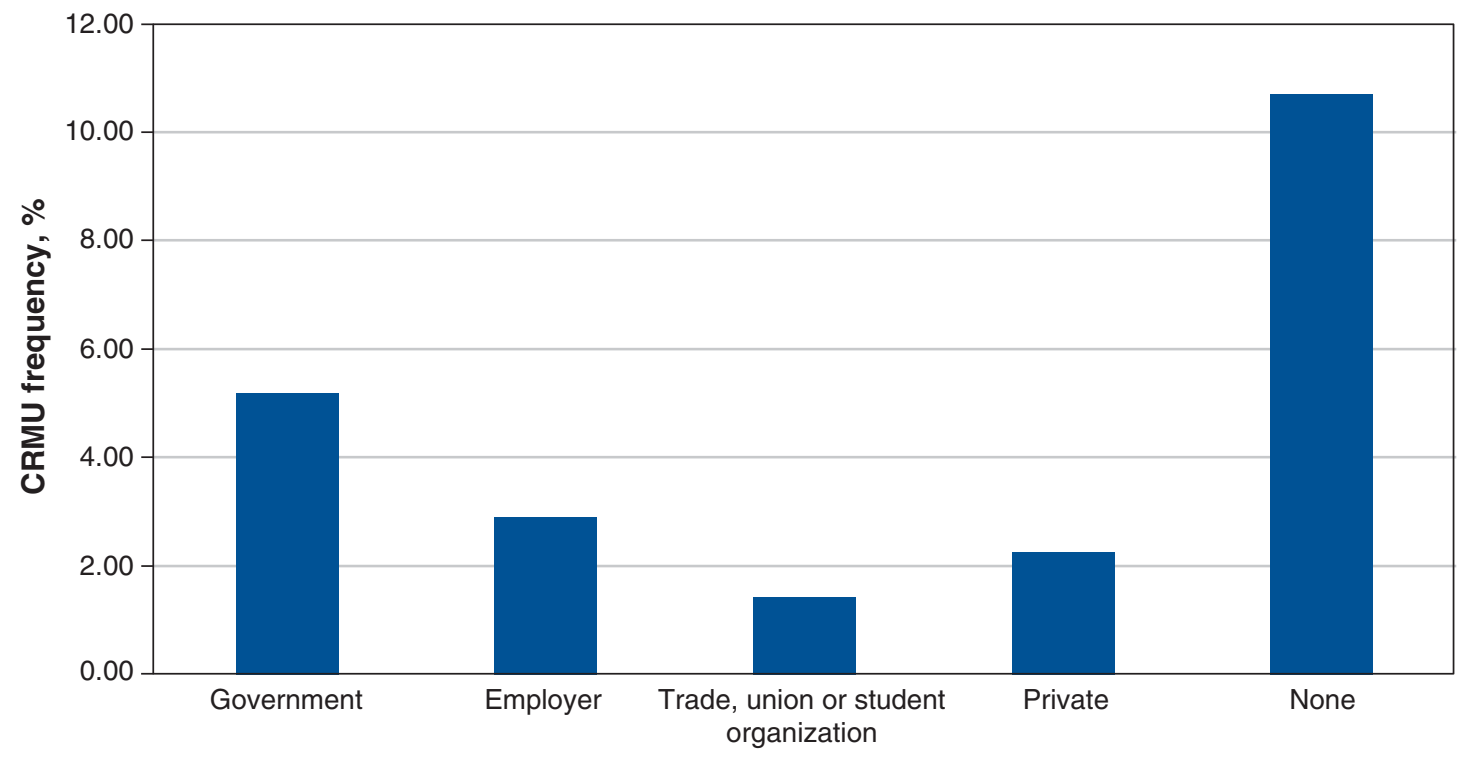

Type of prescription medication coverage

Figure 1: Frequency of cost-related medication underuse (CRMU) according to the type of medication insurance coverage. 


\begin{tabular}{|c|c|c|c|}
\hline Variable & $\begin{array}{l}\text { Weighted } \\
\text { population with } \\
\text { CRMU, \% }\end{array}$ & $\begin{array}{c}\text { Weighted } \\
\text { population without } \\
\text { CRMU, \% }\end{array}$ & $p$ value \\
\hline Age, yr & & & $<0.001$ \\
\hline $18-64$ & 67.1 & 46.1 & \\
\hline$\geq 65$ & 32.9 & 53.9 & \\
\hline Sex & & & $<0.001$ \\
\hline Male & 25.9 & 40.7 & \\
\hline Female & 74.1 & 59.3 & \\
\hline Racial background & & & $<0.001$ \\
\hline White & 82.7 & 89.0 & \\
\hline Indigenous & 10.4 & 3.1 & \\
\hline Other & 6.9 & 7.9 & \\
\hline Marital status & & & $<0.001$ \\
\hline Married & 33.2 & 58.0 & \\
\hline Unmarried & 66.8 & 42.0 & \\
\hline Self-perceived health & & & $<0.001$ \\
\hline Excellent & 5.1 & 10.7 & \\
\hline Very good & 11.8 & 29.1 & \\
\hline Good & 34.6 & 35.4 & \\
\hline Fair & 27.0 & 16.2 & \\
\hline Poor & 21.5 & 8.6 & \\
\hline Self-perceived mental health & & & $<0.001$ \\
\hline Excellent & 14.0 & 30.4 & \\
\hline Very good & 32.1 & 35.2 & \\
\hline Good & 30.5 & 25.5 & \\
\hline Fair & 18.8 & 7.0 & \\
\hline Poor & 4.6 & 1.9 & \\
\hline Total household income, \$ & & & $<0.001$ \\
\hline$<20000$ & 19.4 & 9.0 & \\
\hline $20000-39999$ & 32.4 & 20.1 & \\
\hline $40000-59999$ & 21.0 & 17.4 & \\
\hline $60000-79999$ & 11.6 & 14.3 & \\
\hline$\geq 80000$ & 15.6 & 39.2 & \\
\hline Education & & & 0.923 \\
\hline Less than secondary school & 16.9 & 17.9 & \\
\hline Secondary school & 24.0 & 23.2 & \\
\hline Postsecondary education & 59.1 & 58.9 & \\
\hline $\begin{array}{l}\text { Working status (previous } \\
\text { week) }\end{array}$ & & & 0.004 \\
\hline Worked at a job or business & 34.0 & 41.5 & \\
\hline $\begin{array}{l}\text { Absent from work or } \\
\text { business }\end{array}$ & 3.6 & 5.1 & \\
\hline Did not have a job & 62.4 & 53.4 & \\
\hline
\end{tabular}




\begin{tabular}{|c|c|c|c|}
\hline Variable† & $\begin{array}{l}\text { Weighted } \\
\text { population with } \\
\text { CRMU, \% }\end{array}$ & $\begin{array}{c}\text { Weighted } \\
\text { population without } \\
\text { CRMU, \% }\end{array}$ & $p$ value \\
\hline $\begin{array}{l}\text { Insurance for prescription } \\
\text { medications }\end{array}$ & & & $<0.001$ \\
\hline Yes & 65.0 & 84.5 & \\
\hline No & 35.0 & 15.5 & \\
\hline Cancer status & & & 0.941 \\
\hline Current diagnosis & 20.8 & 20.6 & \\
\hline Survivor & 79.2 & 79.4 & \\
\hline $\begin{array}{l}\text { Overnight hospital visits in the } \\
\text { previous } 12 \text { months }\end{array}$ & & & $<0.001$ \\
\hline Yes & 27.5 & 14.4 & \\
\hline No & 72.5 & 85.6 & \\
\hline $\begin{array}{l}\text { Worried food would run out in } \\
\text { the previous } 12 \text { months }\end{array}$ & & & $<0.001$ \\
\hline Often true & 23.2 & 1.8 & \\
\hline Sometimes true & 19.5 & 4.4 & \\
\hline Never true & 57.3 & 93.8 & \\
\hline Comorbidities $\ddagger$ & & & $<0.001$ \\
\hline No comorbidities & 5.9 & 15.8 & \\
\hline One comorbidity & 19.0 & 23.1 & \\
\hline More than 1 comorbidity & 75.1 & 61.1 & \\
\hline \multicolumn{4}{|c|}{$\begin{array}{l}\text { *Of the } 109660 \text { respondents to the Canadian Community Health Survey 2015/16, } 8581 \text { eligible participants } \\
\text { were included in the current study ( } 460 \text { participants [weighted frequency 5\%] who reported CRMU; } 8121 \\
\text { participants who did not report CRMU [weighted frequency 95\%]). } \\
\text { †Some respondents were missing information for the following variables: marital status }(n=20) \text {, self- } \\
\text { reported health }(n=40) \text {, self-reported mental health }(n=21) \text {, income }(n=8) \text {, education }(n=119) \text {, food } \\
\text { security }(n=3033) \text {, working status }(n=2555) \text {, comorbidities }(n=353) \text {. } \\
\text { †Comorbidities: asthma, chronic obstructive pulmonary disease, sleep apnea, fibromyalgia, arthritis, } \\
\text { osteoporosis, hypertension, dyslipidemia, heart disease, stroke, diabetes mellitus, migraine, mood disorder } \\
\text { and anxiety disorder. }\end{array}$} \\
\hline
\end{tabular}

\section{Interpretation}

Our evaluation of the patterns of CRMU among Canadian adults with cancer in a contemporary population-based study suggests that CRMU is not uncommon in this population. The toll of the problem seems to be unequally carried by women, racial minorities and younger $(<65 \mathrm{yr})$ uninsured adults. These results should lead to a real discussion about the role of a national pharmacare program in covering expenses for prescription medications for these patients.

Canada prides itself on its publicly funded health care system that provides coverage for all interventions deemed medically necessary. In the context of cancer care, the public health care system covers the expenses of necessary investigations and most of the approved anticancer treatments. However, people with a history of cancer may have other medical conditions requiring treatment with medications that may not be covered by provincial health insurance. Given the association of cancer diagnoses and treatments with unemployment and long-term disability,,$^{15}$ consequences can be severe for patients dealing with the short- or long-term effects of cancer and its treatment and who are unable to afford medications. Equally alarming is our observation that many people with CRMU are struggling with food insecurity, given recent data suggesting higher mortality among Canadians struggling with food insecurity. ${ }^{16,17} \mathrm{It}$ is possible that, among this group, the lack of financial means to provide for food is an indirect result of medication expenses. It is also important to highlight that linking drug plans to employment means that people who are chronically unemployed or underemployed (including many patients with cancer and survivors) are going to be affected disproportionately. This is an important argument in favour of a universal drug coverage plan, regardless of employment status.

The toll of these expenses seems to be unequally carried by some vulnerable subgroups, including women and racial minorities, which may be the result of the lower socioeconomic status of these groups and subsequent inability to cover the expenses of medications. ${ }^{18}$ This is also consistent with previous studies 


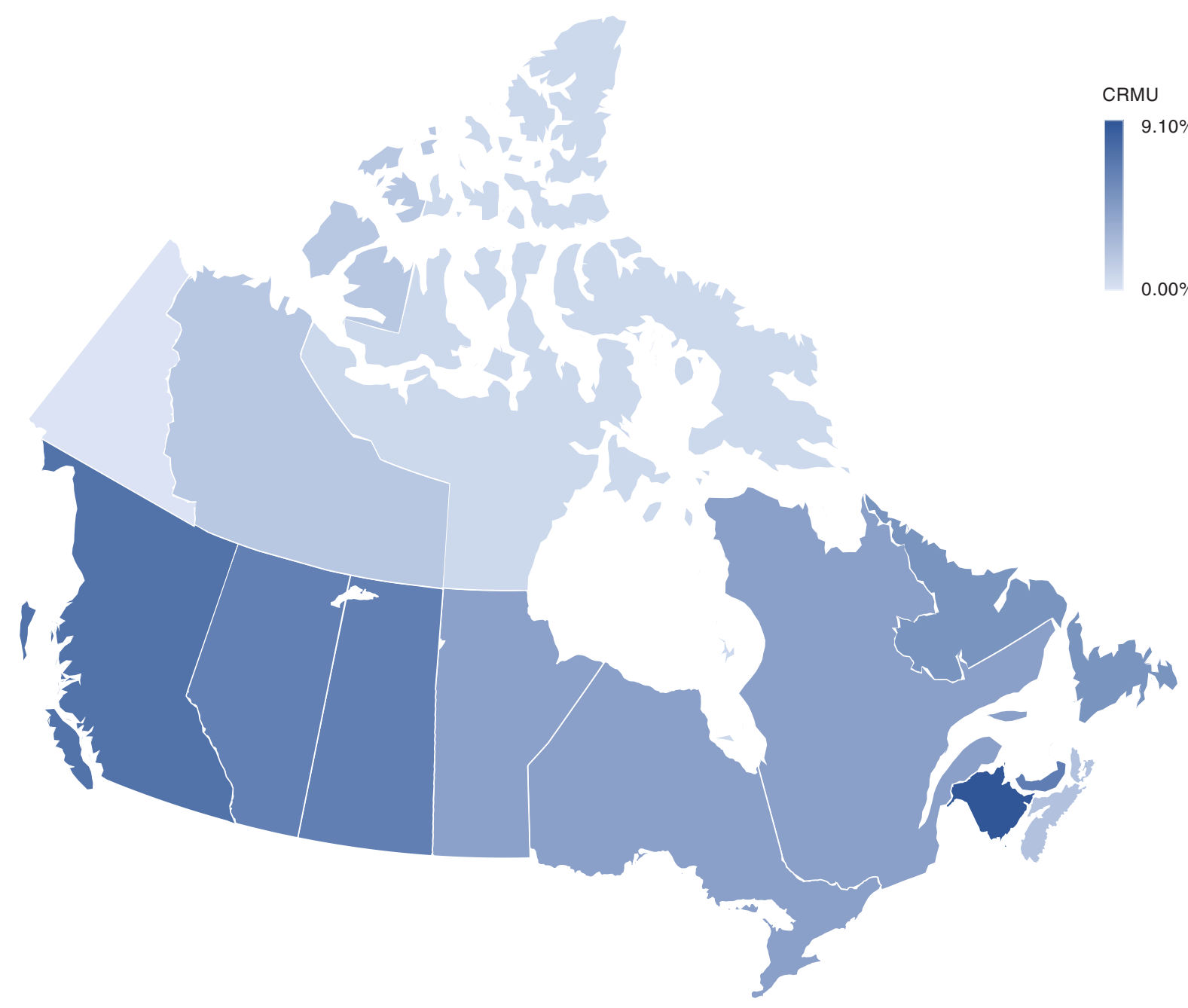

Figure 2: Geographic distribution of cost-related medication underuse (CRMU) among adults with a history of cancer across different Canadian jurisdictions.

suggesting worse cancer-specific and noncancer-specific outcomes of patients with cancer of lower socioeconomic status compared with those of higher socioeconomic status. ${ }^{19-22}$

Younger $(<65 \mathrm{yr})$ adults with a history of cancer seem to be particularly affected by CRMU, which may be related to the fact that, within most Canadian jurisdictions, old age security plans provide some form of prescription medication coverage. We observed, however, that people with governmental insurance still have considerable CRMU (5.2\%, Figure 1). This type of insurance is usually provided to older people as part of old age security programs, as well as to those on disability and income supports. We need to evaluate why governmental coverage is underperforming compared with other forms of coverage. Of note here is that many people with drug plans still have copayments, and if some of the drugs are expensive, like many supportive medications for patients with cancer, they still may not be able to afford the copayment. Moreover, some drug plans have annual or lifetime caps on how much they reimburse participants, leading some people to run out of coverage or to decide not to use up their coverage for this condition. This problem could be exacerbated for plans intended to cover whole families.

Although these data were collected before the COVID-19 pandemic, there have been issues during the pandemic related to dispensing drugs in 1-month supplies, leading to more dispensing fees for patients. Under normal circumstances, many oncologists prescribe supportive cancer care medications to supply all scheduled cycles at once. This may not be feasible in the COVID-19 era; so, these ancillary costs also increase out-of-pocket expenses for many patients with cancer and survivors.

Acknowledging the differences in health care organization and delivery between Canada and the United States, it remains valuable to compare the results of the current study with contemporary US studies evaluating CRMU. In a recent study based on the National Health Interview Survey (2011-2017) in the US, the implementation of patient protection and the Affordable Care Act led to a decrease in CRMU among cancer survivors, particularly those younger than 65 years and those with lower income. ${ }^{23}$ These findings 


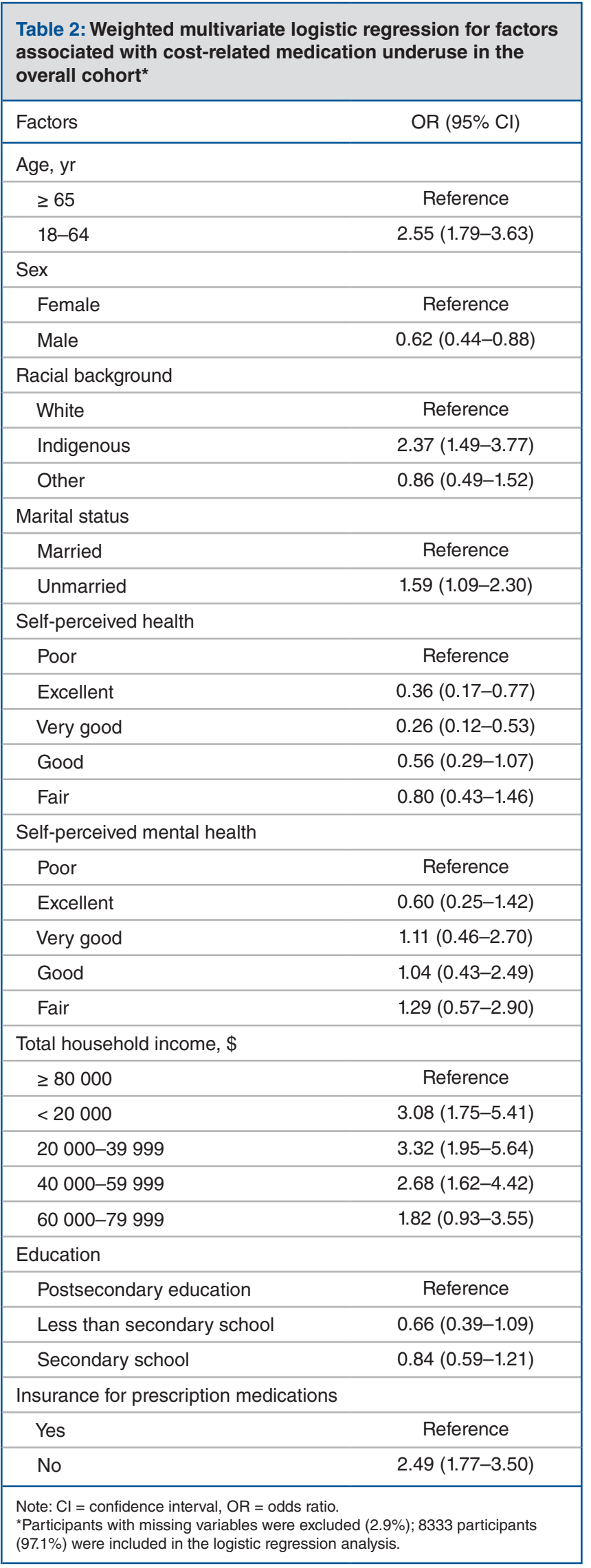

highlight the positive impact of national programs providing medication coverage for vulnerable groups. In another US study, also based on the National Health Interview Survey (2013-2015), adolescent and young adult cancer survivors were more likely to report CRMU and subsequent nonadherence to prescribed medications. ${ }^{13}$

Our results suggest that people with CRMU were more likely to visit emergency departments and be admitted to hospital. Although this may be related to the observed imbalance in baseline comorbidities or other possible confounders, this also might suggest that apparent cost savings from the lack of universal prescription medication coverage may ultimately result in higher costs to public health care systems through hospital admissions and other sequelae. This question needs to be formally addressed in a cost-effectiveness study.

\section{Limitations}

The self-reporting design of the CCHS regarding the diagnosis of cancer, insurance coverage and CRMU might raise some concerns regarding a possible bias in reporting. Although this is a possibility, many studies evaluating CRMU in Canada, the US or elsewhere are based on similar self-reporting surveys (e.g., the National Health Interview Survey in the US). For practical reasons, it is extremely difficult to answer these questions with a sufficiently large size of participants using prospective research designs. As with previously published CCHS studies, information about primary cancer site, treatment and stage are not available. Granular details about the medication being underused, and possible linkage to overall and cancer-specific mortality are also not available. Although these are relevant data, we know the serious consequences of medication nonadherence among patients with cancer, as well as the general population, from previous population-based studies. ${ }^{24-26} \mathrm{~A}$ more recent CCHS data set covering 2017/18 has been recently released. However, complete information about CRMU (variable PEX_090) cannot be found in the 2017/18 data set. These limitations need to be counterbalanced with the strengths of this study, including the contemporaneous nature of data collection, its large sample size, as well as its broad national view, providing information about important interjurisdictional differences in Canada.

\section{Conclusion}

Cost-related medication underuse is not uncommon among adults with cancer in Canada. The toll of the problem seems to be unequally carried by women, racial minorities, and adults younger than 65 years and people who are uninsured. Discussion about a national pharmacare program for people who are uninsured is needed.

\section{References}

1. Canada's health care system. Ottawa: Health Canada; modified 2019 Sept. 17. Available: www.canada.ca/en/health-canada/services/health-care-system/ reports-publications/health-care-system/canada.html (accessed 2020 Aug. 2).

2. Canada Health Act (R.S.C., 1985, c. C-6). Available: https://laws-lois.justice. gc.ca/eng/acts/C-6/ (accessed 2020 Aug. 2).

3. Truong J, Chan KKW, Mai H, et al. The impact of pricing strategy on the costs of oral anti-cancer drugs. Cancer Med 2019;8:3770-81. 
4. Understand how health care works in Canada. Ottawa: Immigration, Refugees and Citizenship Canada; modified 2020 Oct. 28. Available: www.canada.ca/en/ immigration-refugees-citizenship/services/new-immigrants/new-life-canada/ health-care-card.html (accessed 2020 Aug. 2).

5. Gupta S, McColl MA, Guilcher SJ, et al. Cost-related nonadherence to prescription medications in Canada: a scoping review. Patient Prefer Adberence 2018;12:1699-715.

6. Hennessy D, Sanmartin C, Ronksley P, et al. Out-of-pocket spending on drugs and pharmaceutical products and cost-related prescription non-adherence among Canadians with chronic disease. Health Rep 2016;27:3-8.

7. Tamblyn R, Eguale T, Huang A, et al. The incidence and determinants of primary nonadherence with prescribed medication in primary care: a cohort study. Ann Intern Med 2014;160:441-50.

8. Després F, Perreault S, Lalonde L, et al. Impact of drug plans on adherence to and the cost of antihypertensive medications among patients covered by a universal drug insurance program. Can 7 Cardiol 2014;30:560-7.

9. Yabroff KR, Lund J, Kepka D, et al. Economic burden of cancer in the United States: estimates, projections, and future research. Cancer Epidemiol Biomarkers Prev 2011;20:2006-14.

10. de Oliveira C, Weir S, Rangrej J, et al. The economic burden of cancer care in Canada: a population-based cost study. CMA7 Open 2018;6:E1-10.

11. Canadian Community Health Survey: annual component (CCHS) - list of surveys in collection. Ottawa: Statistics Canada; modified 2020 Dec. 29. Available: www.statcan.gc.ca/eng/survey/household/3226 (accessed 2019 Dec. 31).

12. Community Health Survey: annual component (CCHS). Available: www23. statcan.gc.ca/imdb/p2SV.pl? Function=getSurvey \&SDDS=3226 (accessed 2020 Dec. 12)

13. Kaul S, Avila JC, Mehta HB, et al. Cost-related medication nonadherence among adolescent and young adult cancer survivors. Cancer 2017;123: 2726-34.

14. Canadian Institutes of Health Research; Natural Sciences and Engineering Research Council of Canada; Social Sciences and Humanities Research Council. Tri-Council Policy Statement: ethical conduct for research involving humans. Ottawa: Secretariat on Responsible Conduct of Research; 2019. Available: https://ethics.gc.ca/eng/policy-politique_tcps2-eptc2_2018.html (accessed 2020 Sept. 23).

15. de Boer AGEM, Taskila T, Ojajärvi A, et al. Cancer survivors and unemployment: a meta-analysis and meta-regression. 7AMA 2009;301:753-62.

16. Men F, Gundersen C, Urquia ML, et al. Association between household food insecurity and mortality in Canada: a population-based retrospective cohort study. CMA7 2020;192:E53-60.

17. Gundersen C, Tarasuk V, Cheng J, et al. Food insecurity status and mortality among adults in Ontario, Canada. PLoS One 2018;13:e0202642.

18. Densmore R, Hajizadeh $M$, Hu $M$. Trends in socio-economic inequalities in bladder cancer incidence in Canada: 1992-2010. Can 7 Public Health 2019;110:722-31.

19. Abdel-Rahman O. Treatment choices and outcomes of non-metastatic hepatocellular carcinoma patients in relationship to neighborhood socioeconomic status: a population-based study. Int 7 Clin Oncol 2020;25:861-6.
20. Abdel-Rahman O. Socioeconomic predictors of suicide risk among cancer patients in the United States: a population-based study. Cancer Epidemiol 2019;63:101601

21. Global Burden of Disease Cancer Collaboration; Fitzmaurice C, Abate D, Abbasi N, et al. Global, regional, and national cancer incidence, mortality, years of life lost, years lived with disability, and disability-adjusted life-years for 29 cancer groups, 1990 to 2017: a systematic analysis for the global burden of disease study. 7AMA Oncol 2019;5:1749-68.

22. Abdel-Rahman O. Prognostic impact of socioeconomic status among patients with malignant melanoma of the skin: a population-based study. 7 Dermatolog Treat 2020;31:571-5.

23. Barnes JM, Johnson KJ, Adjei Boakye E, et al. Impact of the Patient Protection and Affordable Care Act on cost-related medication underuse in nonelderly adult cancer survivors. Cancer 2020;126:2892-9.

24. Ho PM, Rumsfeld JS, Masoudi FA, et al. Effect of medication nonadherence on hospitalization and mortality among patients with diabetes mellitus. Arch Intern Med 2006;166:1836-41.

25. Shin JW, Jung SW, Lee SB, et al. Medication nonadherence increases hepatocellular carcinoma, cirrhotic complications, and mortality in chronic hepatitis B patients treated with entecavir. Am 7 Gastroenterol 2018;113:998-1008.

26. Gathright EC, Dolansky MA, Gunstad J, et al. The impact of medication nonadherence on the relationship between mortality risk and depression in heart failure. Health Psychol 2017;36:839-47.

Affiliation: Department of Oncology, University of Alberta and Cross Cancer Institute, Edmonton, Alta.

Contributors: Both authors contributed to the conception and design of the work. Omar Abdel-Rahman acquired, analyzed and interpreted the data, and drafted the manuscript. Both authors revised the manuscript critically for important intellectual content, gave final approval of the version to be published and agreed to be accountable for all aspects of the work.

Content licence: This is an Open Access article distributed in accordance with the terms of the Creative Commons Attribution (CC BY-NC-ND 4.0) licence, which permits use, distribution and reproduction in any medium, provided that the original publication is properly cited, the use is noncommercial (i.e., research or educational use), and no modifications or adaptations are made. See: https://creativecommons.org/licenses/ by-nc-nd/4.0/

Data sharing: This study is based on data sets obtained from the Canadian Community Health Survey. Interested researchers can access original data sets through Statistics Canada.

Supplemental information: For reviewer comments and the original submission of this manuscript, please see www.cmajopen.ca/content/9/2/ E474/suppl/DC1. 